\title{
A Quantitative Risk Assessment Methodology of Electric CPS
}

\author{
ZHANG Jiaxi and SONG Yu \\ School of Control and Computer Engineering, North China Electric Power University, Baoding, China
}

\begin{abstract}
To mitigate the security risk level of CPS (cyber physical power system) and achieve efficient operation of power system, this paper focused on the CPS risk assessment. Based on the study of CPS risk assessment theories and electric CPS security features, this paper analyzed and compared the existing electric CPS risk researches, and found that the limitation was the lack of specific quantitative methods. By introducing the integrated fuzzy risk assessment methodology, a security risk quantitative evaluation methodology of electric CPS was designed. Firstly, a systematic literature review was conducted, and relevant standards were collected; then we used AHP (analytic hierarchy process) to analyze the weights of each parameter; and finally integrated various parameters and calculated the overall risk rating of the system. The data of an electric CPS were used to apply this methodology and the result confirmed the feasibility.
\end{abstract}

Key words: Electric CPS, risk assessment, TFN, AHP.

\section{Introduction}

The deep integration of power systems and cyber systems is a major trend in the development of the current electricity system. CPS (cyber-physical systems) integrates computing resources and physical systems, in order to achieve the perception, control and information services of large engineering systems. The CPS used in power systems will effectively realize the intelligent development of systems. However, electric CPS has a high complexity, which is characterized by: (1) The range of information collection is much larger than than that of smart grid; (2) Electric CPS communication network is composed of wired and wireless networks; (3) Many distributed computing devices exit; (4) The control center is connected with and directly control a variety of distributed power sources and the load device [1]. Therefore, the risk sources are quite diverse. Depending on the size of risk, we determine the degree of attention, so risk quantification is essential

Corresponding author: Jiaxi Zhang, graduate student, research fields: software engineering, artificial intelligence. E-mail: 283873633@QQ.com. for decision-making.

With the development of power systems, security issues become more prominent, so the risk assessment of CPS is important. Most of the power system security risk assessment study in Refs. [2-11] to quantify physical and information systems separatedly. It's lack of systematic quantitative methods, and it's not conducive to the overall decision-making. Therefore, we introduce fuzzy risk assessment methods to systematically analyze the risk of electric CPS.

The paper is organized as follows: Section 2 explains risk analysis of electric CPS; Section 3 contains the integrated fuzzy risk assessment methodology; Section 4 is the conclusion.

\section{Risk Analysis of Electric CPS}

Power system is a complex system, its supporting environment includes the heterogeneous computer systems in dispatch center at all levels, local area networks and the power system industry extranet, connecting the local area networks [12]. CPS is a binary heterogeneous complex network and its security issues include network security and physical 
security, as well as the coupling risk [13]. Given the special nature of electric CPS, considering various factors on physical and cyber layers, we take a thermal power plant as an example. Referring to Ref. [14], Table 1 lists the electric CPS risk assessment parameters, written as $\mathrm{Ci}$.

\section{Integrated Fuzzy Risk Assessment Methodology}

\subsection{TFN}

TFN (triangular fuzzy number) is a method to turn uncertain fuzzy linguistic variables into certain values.

If the membership function of fuzzy number $A$ is

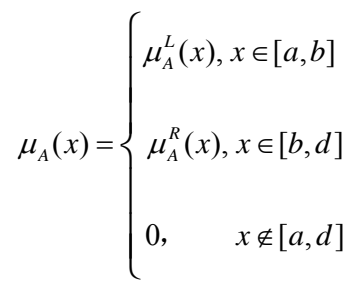

In Eq. (1): $\mu_{A}^{L}(x):[a, b] \rightarrow[0,1]$, continuously and strictly increases; $\mu_{A}^{R}(x):[b, d] \rightarrow[0,1]$, continuously and strictly decreases; $a<b<d$ and $a, b, d \in R$. If $\mu_{A}^{L}(x)$ and $\mu_{A}^{R}(x)$ are linear functions of Eq. (2), we call A TFN, and record as $\mathrm{A}=(\mathrm{a}, \mathrm{b}, \mathrm{d})$, where $\mathrm{a}$ is the value of the lower limit, $b$ is the possible value, $d$ is the upper limit [15].

$$
\mu_{A}(x)=\left\{\begin{array}{l}
\frac{1}{b-a} x-\frac{a}{b-a}, x \in[a, b] \\
\frac{1}{b-d} x-\frac{d}{b-d}, x \in[b, d] \\
0, \quad x \in(-\infty, a] \cup[d,+\infty)
\end{array}\right.
$$

3.1.1 Determining the Quantitative Status Indicator Scoring Models and Membership Functions

Risk assessment includes two aspects, namely the severity and probability. In reality, due to the uncertainty and lack of information, there are certain difficulties to assess these factors. Therefore a lot of evaluation results use linguistic variables, such as high, medium, low. In this study, the qualitative standard uses TFN to express the ambiguity of object. Table 2 describes the qualitative evaluation of systems.
3.1.2 Determining the Qualitative Status Index Memberships

Risk parameter rating is constituted by the linguistic variables, including V1, V2, V3, V4, V5, V6, V7, where, $\mathrm{V} 1=$ quite low, $\mathrm{V} 2=$ very low, $\mathrm{V} 3=$ low, V4 = moderate, $\mathrm{V} 5=$ high, $\mathrm{V} 6=$ very high, $\mathrm{V} 7=$ quite high. These language variables membership function is defined by TFN, shown as Eq. (3).

$$
\begin{aligned}
& V_{1}=\left(0,0, \frac{1}{6}\right) \quad \mu_{N 1}(x)=\left\{\begin{aligned}
1-6 x, & 0 \leq x<\frac{1}{6}, \\
0, & \frac{1}{6} \leq x \leq 1,
\end{aligned}\right. \\
& V_{n}=\left(\frac{n-2}{6}, \frac{n-1}{6}, \frac{n}{6}\right) \mu_{N 1}(x)= \begin{cases}0, & 0 \leq x<\frac{n-2}{6}, \\
6 x-(n-2), \frac{n-2}{6} \leq x<\frac{n-1}{6}, \\
n-6 x, & \frac{n-1}{6} \leq x \leq \frac{n}{6}, \\
0, & \frac{n}{6} \leq x \leq 1,\end{cases} \\
& V_{7}=\left(\frac{5}{6}, 1,1\right) \quad \mu_{N 1}(x)= \begin{cases}0, & 0 \leq x<\frac{5}{6}, \\
6 x-5, & \frac{5}{6} \leq x \leq 1,\end{cases} \\
& n=2,3,4,5,6
\end{aligned}
$$

\subsubsection{Establishing Fuzzy Evaluation Matrix}

Fuzzy risk evaluation matrix is established by $\mathrm{Ci} \times$ V. A fuzzy evaluation matrix $M(\mathrm{C} 1)$ can be calculated as follows:

$$
M\left(C_{1}\right)=\left(\begin{array}{lll}
V\left(s_{11}, l_{11}, 1\right) & V\left(s_{11}, l_{11}, 2\right) \ldots V\left(s_{11}, l_{11}, 7\right) \\
V\left(s_{12}, l_{12}, 1\right) & V\left(s_{12}, l_{12}, 2\right) \ldots V\left(s_{12}, l_{12}, 7\right) \\
\ldots & \ldots & \ldots \\
V\left(s_{18}, l_{18}, 1\right) & V\left(s_{18}, l_{18}, 2\right) \ldots V\left(s_{18}, l_{18}, 7\right)
\end{array}\right) C_{11} C_{12}
$$

In the same way, we can construct fuzzy evaluation matrix $\mathrm{M}(\mathrm{C} 2), \mathrm{M}(\mathrm{C} 3), \mathrm{M}(\mathrm{C} 4)$ and $\mathrm{M}(\mathrm{C} 5)$ for risk category $\mathrm{C} 2, \mathrm{C} 3, \mathrm{C} 4$ and $\mathrm{C} 5$ respectively.

\subsection{AHP}

The AHP is a good way to solve the problem of multi-parameter decision. Suppose the parent function $\mathrm{f}$ is divided into five sub-functions $\mathrm{fl-f5}$, followed by the corresponding risk weight $\omega 1-\omega 5$. Specifically, the risk weight steps are as follows: 
Table 1 Risk assessment parameters of electric CPS.

\begin{tabular}{|c|c|c|}
\hline \multirow{6}{*}{ physical layerC1 } & major architecture factors $\mathrm{C} 11$ & $\begin{array}{l}\text { surrounding architecture environment C111 } \\
\text { Storage warehouse and coal pier C112 } \\
\text { The main control room C113 } \\
\text { Residential building factor C114 }\end{array}$ \\
\hline & fire management factors $\mathrm{C} 12$ & $\begin{array}{l}\text { Fire alarm systems C121 } \\
\text { Flammable gas leak detector C122 } \\
\text { Automatic fire extinguishing systemC123 } \\
\text { Mechanical exhaust systemC124 } \\
\text { Fire truck settingC125 } \\
\text { Extinguishing equipment C126 } \\
\text { Fire hydrant settingC127 } \\
\text { Distance from the local fire brigade C128 } \\
\text { Fire water setting C129 }\end{array}$ \\
\hline & main risk factors $\mathrm{C} 13$ & $\begin{array}{l}\text { Fuel C131 } \\
\text { Boiler systems C132 } \\
\text { Turbine generator set C133 } \\
\text { Electrical systems C134 } \\
\text { Special risk factors C135 } \\
\end{array}$ \\
\hline & social environment factors $\mathrm{C} 14$ & $\begin{array}{l}\text { Set of operators on duty C141 } \\
\text { Theft factor C142 } \\
\text { Public responsibility factor C143 } \\
\text { Security situation around the plant C144 } \\
\text { Temporary employer's liability factor C145 }\end{array}$ \\
\hline & secrurity managementC15 & $\begin{array}{l}\text { Safety management C151 } \\
\text { Staff safety education C152 } \\
\text { Duty system of special operation C153 } \\
\text { Duty system of security C154 } \\
\text { Regular safety inspections C155 } \\
\text { Emergency mechanism C156 } \\
\end{array}$ \\
\hline & nature environment factors $\mathrm{C} 16$ & $\begin{array}{l}\text { Geological Environment C161 } \\
\text { Hydrological Environment C162 } \\
\text { Meteorological environment C163 } \\
\end{array}$ \\
\hline \multirow{9}{*}{ cyber layerC2 } & Malicious codeC21 & $\begin{array}{l}\text { Virus C211 } \\
\text { Worms C212 } \\
\text { Trojans C213 } \\
\text { XSS C214 } \\
\text { Hybrid C215 } \\
\end{array}$ \\
\hline & Hardware failure C22 & \\
\hline & Unwanted accessC23 & $\begin{array}{l}\text { Fraudulent use of other users C231 } \\
\text { Illegal modification of their own user permissions C232 } \\
\text { Occupy of two roles C233 } \\
\text { Damage of access control systems C234 } \\
\text { Not-turned-off interfaces C235 } \\
\text { Intercepted and modified during transmission C236 } \\
\text { Channel interference of information content C237 } \\
\text { The action during very time C238 }\end{array}$ \\
\hline & Too many service requests C24 & $\begin{array}{l}\text { Increase in service under normal circumstances C241 } \\
\text { Malicious denial of service attack C242 }\end{array}$ \\
\hline & Data channel failure C25 & \\
\hline & Damage from people C26 & \\
\hline & Users denying operations C27 & $\begin{array}{l}\text { Users denying specific operation C271 } \\
\text { Users denying sending / receiving information C272 }\end{array}$ \\
\hline & Fake device $\mathrm{C} 28$ & \\
\hline & Problematic inputC29 & $\begin{array}{l}\text { User misuse C291 } \\
\text { Malicious input C292 } \\
\text { Interaction problem C293 } \\
\end{array}$ \\
\hline
\end{tabular}


Table 2 Linguistic classification of grades of hazard factors and their corresponding TFNs.

\begin{tabular}{llll}
\hline Ranking level & Severity(s) & Likelihood(l) & TFNs \\
\hline 1 & Definitely mild & Definitely low & $(0.0,0.0,0.1)$ \\
2 & Extremely mild & Extremely low & $(0.0,0.1,0.2)$ \\
3 & Quite mild & Quite low & $(0.1,0.2,0.3)$ \\
4 & Mild & Low & $(0.2,0.3,0.4)$ \\
5 & Slightly mild & Slightly low & $(0.3,0.4,0.5)$ \\
6 & Moderate & Moderate & $(0.4,0.5,0.6)$ \\
7 & Slightly severe & Slightly high & $(0.5,0.6,0.7)$ \\
8 & Severe & High & $(0.6,0.7,0.8)$ \\
9 & Quite severe & Quite high & $(0.7,0.8,0.9)$ \\
10 & Extremely severe & Extremely high & $(0.8,0.9,1.0)$ \\
11 & Definitely severe & Definitely high & $(0.9,1.0,1.0)$ \\
\hline
\end{tabular}

(1) Consult experts in the field, compare f1-f5 in pairs based on nine scaling method, and construct judgment matrix Z, shown as Eq. (5).

$$
Z=\left[\begin{array}{cccccc}
1 & z_{12} & z_{13} & z_{14} & z_{15} & \omega_{1} \\
z_{21} & 1 & z_{23} & z_{24} & z_{25} & \omega_{2} \\
z_{31} & z_{32} & 1 & z_{34} & z_{35} & \omega_{3} \\
z_{41} & z_{42} & z_{43} & 1 & z_{45} & \omega_{4} \\
z_{51} & z_{52} & z_{53} & z_{54} & 1 & \omega_{5}
\end{array}\right]
$$

(2) Adopt sum-product method [16] to get eigenvectors of a judgment matrix. Firstly, each column element of $\mathrm{Z}$ goes through a normalization process:

$$
\overline{z_{i j}}=z_{i j} /\left(\sum_{i=1}^{n} z_{i j}\right), \quad j=1,2,3, \ldots, n
$$

Secondly, add the normalized elements of each row:

$$
W_{i}=\left(\sum_{j=1}^{n} \overline{Z_{i j}}\right), \quad i=1,2,3, \ldots, n
$$

Finally, the vector $W=\left[W_{1}, W_{2}, \ldots, W_{n}\right]^{T}$ is normalized, i.e., risk weights:

$$
\omega_{i}=W_{i} /\left(\sum_{j=1}^{n} W_{j}\right), \quad i=1,2, \ldots, n
$$

\subsection{Construction of the Overall Risk Assessment Model}

In order to assess the system's overall risk, weight of all risk factors, risk categories and their associated parameters have to be considered in the assessment process. Suppose Wi and Wij are the relative weight of the main risk categories and their associated parameters, $g(s, 1)$ is the risk rating of each parameter, determined by $\mathrm{s}$ and 1 from Table 2 . Here is the three-step fuzzy evaluation method to obtain the overall risk rating.

Step 1, the overall risk assessment of $\mathrm{C} 1$ is shown as Eq. (9).

$$
\begin{aligned}
& (R(1,1), R(1,2), R(1,3), R(1,4), R(1,5), R(1,6), R(1,7))_{1 \times 7} \\
& =\left(W_{11}, W_{12}, W_{13}, W_{14}, W_{15}, W_{16}, W_{17}, W_{18}\right) \times M\left(C_{1}\right)_{8 \times 7}
\end{aligned}
$$

where, $R(1, n)=\sum_{k-1}^{8} W_{1 k} \times V\left(s_{1 k}, l_{1 k}, n\right)$ for $n=1,2, \ldots, 7$

$$
R(1)=(R(1,1), R(1,2), R(1,3), R(1,4), R(1,5), R(1,6), R(1,7)) \quad \text { is }
$$
expressed as the overall risk assessment of $\mathrm{C} 1$ in the first step. Similarly, R(2), R(3), R(4) and R (5) are the overall risk vectors of $\mathrm{C} 2, \mathrm{C} 3, \mathrm{C} 4$ and $\mathrm{C} 5$ in the first step .

Step 2, as shown in Eq. (10):

$$
\begin{aligned}
& (R(1), R(2), R(3), R(4), R(5), R(6), R(7)) \\
& =\left(W_{1}, W_{2}, W_{3}, W_{4}, W_{5}\right)_{1 \times 5} \times(R 1 R 2 R 3 R 4 R 5)^{\prime}
\end{aligned}
$$

where, $R 2(n)=(R(1), R(2), R(3), R(4), R(5), R(6), R(7))$.

Step 3 , by using the gravity method the final overall risk rating is defuzzificated:

$$
\text { Rate }=\sum_{n=1}^{7} V_{G}(n) \times R 2(n)
$$

Specifically, the integrated fuzzy risk assessment method of electric CPS includes:

(1) Determine the power system to be evaluated, functionally decompose it, and collect relevant parameters; 
(2) Calculate the risk level of each sub-parameter. First, express severity s and likelihood 1 by TFN and multiply them to get the risk level $\mathrm{g}$;

(3) Use AHP to analyze parameter weights. Firstly, based on nine scaling method to build judgment matrix $Z$, then use sum-product method to calculate feature vectors, normalize them to get risk weights $\mathrm{W}$;

(4) Construct a risk assessment hierarchy table, consider the various risk levels and weights to get the overall risk assessment vector by fuzzy evaluation matrix, defuzzificate them and obtain specific values.

\section{Case Study}

We take a CPS system in a thermal power plant as an example to evaluate quantitative risk. Referring to classification of parameters in Table 1, firstly we use the nine scaling method to evaluate weight of risks, and by building z-matrix, using the method in section 3.2, we get their own weight. Table 3 lists the risk weights of the first layer's parameters.

$$
Z=\left[\begin{array}{ccc}
1 & 3 & \omega_{1} \\
1 / 3 & 1 & \omega_{2}
\end{array}\right]
$$

According to the Eq. (17), using sum-product method, we get $\omega_{1}=3 / 4, \omega_{2}=1 / 4$. Similarly, the other parameters of the weight distribution are shown in Table 4.

We take C111 as an example, referring to Table 2, and its rating of severity is 8 , the TFN is $(0.6,0.7,0.8)$; Possibility rating is 4 , and the TFN is $(0.2,0.3,0.4)$. According to equation $6 \mathrm{~g}$ is obtained $(\mathrm{s}, \mathrm{l})=(0.12$, 0.21, 0.32). According to the Eq. (7), through defuzzication, we get $\tilde{g}_{i}=0.217$. Likewise other risk ratings are shown in Table 5.

Table 3 Risk weights in case scenario.

\begin{tabular}{lll}
\hline Parameters of first layer & $\mathrm{C} 1$ & $\mathrm{C} 2$ \\
\hline $\mathrm{C} 1$ & 1 & 3 \\
$\mathrm{C} 2$ & $1 / 3$ & 1 \\
\hline
\end{tabular}

Table 4 Weight distribution of each parameter.

\begin{tabular}{|c|c|c|c|c|c|c|c|}
\hline 2nd layer & $\mathrm{w}$ & 3rd layer & W & 2nd & $\mathrm{w}$ & $3 \mathrm{rd}$ & w \\
\hline & & C111 & 0.055 & & & C161 & 0.648 \\
\hline & & C112 & 0.564 & $\mathrm{C} 16$ & 0.0956 & $\mathrm{C} 162$ & 0.122 \\
\hline \multirow[t]{6}{*}{$\mathrm{C} 11$} & 0.0503 & C113 & 0.118 & & & C163 & 0.229 \\
\hline & & C114 & 0.263 & & & $\mathrm{C} 211$ & 0.047 \\
\hline & & C121 & 0.149 & & & $\mathrm{C} 212$ & 0.142 \\
\hline & & $\mathrm{C} 122$ & 0.089 & $\mathrm{C} 21$ & 0.2100 & $\mathrm{C} 213$ & 0.093 \\
\hline & & C123 & 0.213 & & & $\mathrm{C} 214$ & 0.228 \\
\hline & & $\mathrm{C} 124$ & 0.042 & & & $\mathrm{C} 215$ & 0.490 \\
\hline \multirow[t]{7}{*}{$\mathrm{C} 12$} & 0.1595 & C125 & 0.087 & $\mathrm{C} 22$ & 0.0821 & & \\
\hline & & C126 & 0.104 & & & $\mathrm{C} 231$ & 0.140 \\
\hline & & C127 & 0.108 & & & $\mathrm{C} 232$ & 0.098 \\
\hline & & C128 & 0.056 & & & $\mathrm{C} 233$ & 0.118 \\
\hline & & C129 & 0.128 & $\mathrm{C} 23$ & 0.3022 & $\mathrm{C} 234$ & 0.042 \\
\hline & & $\mathrm{C} 131$ & 0.11 & & & $\mathrm{C} 235$ & 0.203 \\
\hline & & $\mathrm{C} 132$ & 0.386 & & & $\mathrm{C} 236$ & 0.104 \\
\hline \multirow[t]{5}{*}{$\mathrm{C} 13$} & 0.4187 & C133 & 0.388 & & & $\mathrm{C} 237$ & 0.087 \\
\hline & & C134 & 0.08 & & & $\mathrm{C} 238$ & 0.184 \\
\hline & & C135 & 0.039 & $\mathrm{C} 24$ & 0.1192 & $\mathrm{C} 241$ & 0.381 \\
\hline & & C141 & 0.491 & & & $\mathrm{C} 242$ & 0.619 \\
\hline & & C142 & 0.232 & $\mathrm{C} 25$ & 0.0181 & & \\
\hline
\end{tabular}


(table 4 continued)

\begin{tabular}{|c|c|c|c|c|c|c|c|}
\hline 2nd layer & $\mathrm{w}$ & 3rd layer & $\mathrm{w}$ & $2 \mathrm{nd}$ & $\mathrm{w}$ & $3 \mathrm{rd}$ & $\mathrm{w}$ \\
\hline \multirow[t]{6}{*}{ C14 } & 0.0555 & C143 & 0.092 & $\mathrm{C} 26$ & 0.0523 & & \\
\hline & & C144 & 0.138 & & & $\mathrm{C} 271$ & 0.524 \\
\hline & & C145 & 0.047 & $\mathrm{C} 27$ & 0.1287 & $\mathrm{C} 272$ & 0.476 \\
\hline & & C151 & 0.424 & $\mathrm{C} 28$ & 0.0231 & & \\
\hline & & $\mathrm{C} 152$ & 0.255 & & & C291 & 0.129 \\
\hline & & $\mathrm{C} 153$ & 0.031 & $\mathrm{C} 29$ & 0.0643 & $\mathrm{C} 292$ & 0.633 \\
\hline \multirow[t]{3}{*}{$\mathrm{C} 15$} & 0.2204 & $\mathrm{C} 154$ & 0.052 & & & C293 & 0.238 \\
\hline & & $\mathrm{C} 155$ & 0.150 & & & & \\
\hline & & C156 & 0.088 & & & & \\
\hline
\end{tabular}

Table 5 Risk ratings

\begin{tabular}{|c|c|c|c|c|c|c|c|}
\hline Risk & $\mathrm{s}$ & 1 & Rating & Risk & $\mathrm{s}$ & 1 & Rating \\
\hline C111 & 8 & 4 & 0.217 & C156 & 4 & 4 & 0.097 \\
\hline $\mathrm{C} 112$ & 4 & 3 & 0.067 & C161 & 3 & 3 & 0.047 \\
\hline C113 & 5 & 3 & 0.087 & C162 & 6 & 3 & 0.107 \\
\hline C114 & 6 & 4 & 0.157 & $\mathrm{C} 163$ & 3 & 3 & 0.047 \\
\hline $\mathrm{C} 121$ & 8 & 3 & 0.147 & C211 & 6 & 4 & 0.157 \\
\hline $\mathrm{C} 122$ & 6 & 3 & 0.107 & C212 & 4 & 2 & 0.037 \\
\hline $\mathrm{C} 123$ & 4 & 3 & 0.067 & C213 & 7 & 2 & 0.067 \\
\hline $\mathrm{C} 124$ & 9 & 3 & 0.167 & C214 & 5 & 3 & 0.087 \\
\hline C125 & 5 & 4 & 0.127 & $\mathrm{C} 215$ & 5 & 3 & 0.087 \\
\hline $\mathrm{C} 126$ & 8 & 4 & 0.217 & C22 & 6 & 3 & 0.107 \\
\hline C127 & 4 & 3 & 0.067 & $\mathrm{C} 231$ & 6 & 4 & 0.157 \\
\hline C128 & 5 & 3 & 0.087 & C232 & 4 & 4 & 0.097 \\
\hline C129 & 6 & 4 & 0.157 & $\mathrm{C} 233$ & 3 & 3 & 0.047 \\
\hline C131 & 3 & 3 & 0.047 & C234 & 5 & 3 & 0.087 \\
\hline C132 & 5 & 4 & 0.127 & C235 & 7 & 3 & 0.127 \\
\hline C133 & 9 & 3 & 0.167 & $\mathrm{C} 236$ & 3 & 3 & 0.047 \\
\hline C134 & 3 & 3 & 0.047 & $\mathrm{C} 237$ & 6 & 3 & 0.107 \\
\hline C135 & 4 & 3 & 0.067 & C238 & 5 & 4 & 0.127 \\
\hline C141 & 7 & 3 & 0.127 & C241 & 6 & 4 & 0.157 \\
\hline C142 & 6 & 3 & 0.107 & C242 & 7 & 2 & 0.067 \\
\hline C143 & 5 & 4 & 0.127 & $\mathrm{C} 25$ & 3 & 3 & 0.047 \\
\hline C144 & 8 & 4 & 0.217 & $\mathrm{C} 26$ & 5 & 3 & 0.087 \\
\hline C145 & 6 & 4 & 0.157 & $\mathrm{C} 271$ & 9 & 3 & 0.167 \\
\hline $\mathrm{C} 151$ & 3 & 3 & 0.047 & $\mathrm{C} 272$ & 6 & 3 & 0.107 \\
\hline C152 & 5 & 3 & 0.087 & C28 & 5 & 4 & 0.127 \\
\hline C153 & 9 & 3 & 0.167 & C291 & 4 & 4 & 0.097 \\
\hline C154 & 6 & 3 & 0.107 & C292 & 3 & 3 & 0.047 \\
\hline C155 & 5 & 4 & 0.127 & C293 & 6 & 3 & 0.107 \\
\hline
\end{tabular}

Risk rating of $\mathrm{C} 111$ is 0.217 , and according to the Eq. (3), its corresponding membership of seven qualitative scales are $\mathrm{V} 1=0, \mathrm{~V} 2=0.70, \mathrm{~V} 3=0.30$, $\mathrm{V} 4=0, \mathrm{~V} 5=0, \mathrm{~V} 6=0, \mathrm{~V} 7=0$ respectively. Similarly, we get collection of memberships of C112-C114, so to build $\mathrm{M}(\mathrm{C} 11)$ matrix:

$$
M\left(C_{11}\right)=\left[\begin{array}{ccccccc}
0 & 0.70 & 0.30 & 0 & 0 & 0 & 0 \\
0.60 & 0.40 & 0 & 0 & 0 & 0 & 0 \\
0.48 & 0.52 & 0 & 0 & 0 & 0 & 0 \\
0.06 & 0.94 & 0 & 0 & 0 & 0 & 0
\end{array}\right] \begin{aligned}
& C_{111} \\
& C_{112} \\
& C_{113} \\
& C_{114}
\end{aligned}
$$


obtain the weighted risk rating of category $\mathrm{C} 11$ :

$$
\begin{aligned}
R(11) & =\left[\begin{array}{llllll}
0.055 & 0.564 & 0.118 & 0.263
\end{array}\right] \times M\left(C_{11}\right) \\
& =\left[\begin{array}{lllllll}
0.411 & 0.573 & 0.017 & 0 & 0 & 0 & 0
\end{array}\right]_{1 \times 7}
\end{aligned}
$$

Similarly, we construct M (C12), M (C13), M(C14), $\mathrm{M}$ (C15), $\mathrm{M}$ (C16), and calculate to get R(12), R(13), $\mathrm{R}(14), \mathrm{R}(15), \mathrm{R}(16)$ :

$$
\begin{aligned}
& \mathrm{R}(12)=\left[\begin{array}{lllllll}
0.298 & 0.647 & 0.031 & 0 & 0 & 0 & 0
\end{array}\right]_{1 \times 7} \\
& R(13)=\left[\begin{array}{lllllll}
0.253 & 0.750 & 0 & 0 & 0 & 0 & 0
\end{array}\right]_{1 \times 7} \\
& R(14)=\left[\begin{array}{lllllll}
0.226 & 0.732 & 0.041 & 0 & 0 & 0 & 0
\end{array}\right]_{1 \times 7} \\
& R(15)=\left[\begin{array}{lllllll}
0.519 & 0.481 & 0 & 0 & 0 & 0 & 0
\end{array}\right]_{1 \times 7} \\
& R(16)=\left[\begin{array}{lllllll}
0.675 & 0.324 & 0 & 0 & 0 & 0 & 0
\end{array}\right]_{\times>}
\end{aligned}
$$

Next, the weight matrix W1i is multiplied by a matrix of risk ratings, so to get the risk rating of $\mathrm{C} 1$ :

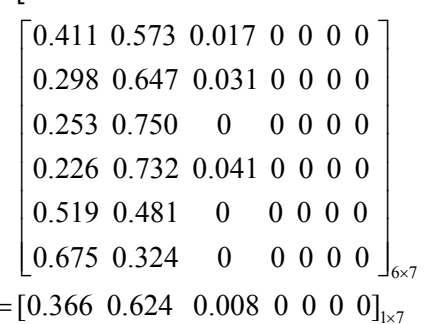$$
R(1)=\left[\begin{array}{llllll}
0.0503 & 0.1595 & 0.4187 & 0.0555 & 0.2204 & 0.0956
\end{array}\right]_{1 \times 6} \times
$$

In the same way, we get

$$
R(2)=\left[\begin{array}{lllllll}
0.396 & 0.597 & 0 & 0 & 0 & 0 & 0
\end{array}\right]_{1 \times 7}
$$

Finally, integrate $\mathrm{C} 1$ and $\mathrm{C} 2$, and we get the overall risk rating:

$$
\begin{aligned}
R 2(n)= & {\left[\begin{array}{lllllll}
0.75 & 0.25
\end{array}\right]_{1 \times 2} \times } \\
& {\left[\begin{array}{llllllll}
0.366 & 0.624 & 0.008 & 0 & 0 & 0 & 0 \\
& 0.396 & 0.597 & 0 & 0 & 0 & 0 & 0
\end{array}\right]_{2 \times 7} } \\
= & {\left[\begin{array}{lllllll}
0.374 & 0.617 & 0.006 & 0 & 0 & 0 & 0
\end{array}\right]_{1 \times 7} }
\end{aligned}
$$

Using the gravity method to process defuzzification, we get integrated fuzzy risk assessment level.

$$
\mathrm{ARI}=0.374 \times 0.0556+0.617 \times 0.1667+0.006 \times
$$$$
0.3333+0 \times 0.5+0 \times 0.6667+0 \times 0.8333+0 \times
$$

$0.9444=0.126$

Therefore, the risk rating of this electric CPS system is 0.126 . Referring to definition of qualitative indicators in section 3.1, it's between V1 (quite low) and V2 (very low).

\section{Conclusion}

Based on fuzzy set theory and AHP, this paper presents a quantitative risk assessment methodology of electric CPS. Through the analysis of risk sources of electric CPS, we take various parameters of CPS into account to evaluate the overall security risk. At last, we use case studies to verify the validity of the method. This approach promotes the change of risk control of electric CPS from afterwards to beforehand, which is of some significance to the smart grid construction.

\section{References}

[1] Zhao, J. H., Wen, F. S., Xue, Y. S., Li, X., and Dong Z. Y. 2010. "Architecture, Implementation and Challenges of Electric CPS." Automation of Electric Power Systems 34: 1-7.

[2] Guo, C. X., Lu, H. B., Yu, B., and Ma, T. T. 2013. “A Survey of Research on Security Risk Assessment of Secondary System." Power System Technology 37: 112-8.

[3] Su, S., Wu, C. J., Ma, J., and Zeng, X. J. 2014. "Attacker's Perspective Based Analysis on Cyber Attack Mode to Cyber-Physical System." Cyber-Physical System (May): 3115-20.

[4] Guo, C. X., Yu. B., Guo, J., Wen, B. J., Zhang, J. J, Zhang, L., Lu, H. B., and Li, B. 2014. "Security Risk Assessment of the IEC61850-based Substation Automation System." Substation Automation System.

[5] Wu, J., Wang, Y., and Wang, R. M. 2013. "Quantitative Risk Evaluation System Design of Electrical Secondary Equipment." Electric Power.

[6] Zhao, J. H., Wen, F. S., Xue, Y. S., and Dong, Z. Y. 2011. "Research of Electric CPS's Modeling Analysis and Control." Automation of Electric Power Systems.

[7] Negnevitsky, M., Nguyen, D. H., and Piekutowski, M. 2015. "Risk Assessment for Power System Operation Planning with High Wind Power Penetration.” IEEE Transactions on Power Systems 30 (3): 1359-68.

[8] Xiao, F., and McCalley, J. D. 2009. "Power System Risk Assessment and Control in a Multiobjective Framework." IEEE Transactions on Power Systems 1 (24): 78-85.

[9] Sridhar, S., Hahn, A., and Govindarasu, M. 2012. "Cyber-Physical System Security for the Electric Power Grid." Proceedings of the IEEE 1 (100): 210-24.

[10] Wang, Y. F., Tang, W, Liu, L. D., and Guo, C. X. 2015. "Construction and Application of Power System's Risk Assessment and Rating System." Automation of Electric Power Systems.

[11] Hing, K. C., Wang, X. J. 2013. Fuzzy Hierarchical Model for Risk Assessment. 236 Gray's Inn Road Floor 6: 
London Ltd.: Springer.

[12] Hu, Y., Xie, X. R., Han, Y. D., Xin, Y. Z. 2005. “A Survey to Design Method of Security Architecture for Power Information Systems." Power System Technology.

[13] Gao, K. L. 2013. "Security Study of Electric CPS." China Information Security.

[14] Wu, Q., Zhao, D. Y., and Chen, Y. H. 2005. "The
Application of AHP-Fuzzy Method in Fire Power Plant.” Industrial Safety and Environmental Protection.

[15] Dubios, D., and Prade, H. 1978. "Operations on Fuzzy Numbers." International Journal of Systems Science (9): 613-26.

[16] Wei, C. P. 1999. "The Optimization Basis and Properties of the Sum-Product Method in AHP." Systems Engineering-Theory \& Practice. 